University of New Haven

University of

New Haven

Digital Commons@ New Haven

Fire Science and Professional Studies Faculty

Publications

Fire Science and Professional Studies

$11-20-2015$

\title{
Enhanced Thermal Decomposition Kinetics of Poly(lactic acid) Sacrificial Polymer Catalyzed by Metal Oxide Nanoparticles
}

Lu Liu

University of Maryland - College Park

Michael R. Zachariah

University of Maryland - College Park

Stanislav I. Stoliarov

University of Maryland - College Park

Jing Li

University of New Haven, jli@newhaven.edu

Follow this and additional works at: http://digitalcommons.newhaven.edu/firescience-facpubs Part of the Emergency and Disaster Management Commons

\section{Publisher Citation}

Liu, L., M. R. Zachariah, S. I. Stoliarov and J. Li (2015). "Enhanced thermal decomposition kinetics of poly(lactic acid) sacrificial polymer catalyzed by metal oxide nanoparticles." RSC Advances 5(123): 101745-101750.

Comments

This is the author's accepted manuscript of the article published in RSC Advances. The final version can be found at http://dx.doi.org/10.1039/ C5RA19303F 


\section{Enhanced thermal decomposition kinetics of Poly (Lactic Acid)}

\section{2 sacrificial polymer catalyzed by metal oxide nanoparticles}

$3 \mathrm{Lu} \mathrm{Liu}^{\mathrm{a}}$, Michael R. Zachariah*ab, Stanislav I. Stoliarov ${ }^{\mathrm{c}}$, Jing Li*d

a. Department of Chemistry and Biochemistry, University of Maryland, College Park, MD 20742, USA

b. Department of Chemical and Biomolecule Engineering, University of Maryland, College Park, MD 20742, USA

c. Department of Fire Protection Engineering, University of Maryland, College Park, MD 20742, USA

d. Department of Fire Science \& Professional Studies, University of New Haven, West Haven, CT, 06516, USA Tel.: +01-203-932-1197; Fax: +01-203-931-6095 E-mail address: jli@newhaven.edu (J. Li).

ABSTRACT: Poly Lactic Acid (PLA) has been used as sacrificial polymer in the fabrication of battery separators and can be employed in 0D-3D Vaporization of a Sacrificial Component (VaSC) fabrication. In this study, $1 \mathrm{wt} \% \mathrm{PLA} / \mathrm{Fe}_{2} \mathrm{O}_{3}, \mathrm{PLA} / \mathrm{CuO}, \mathrm{PLA} / \mathrm{Bi}_{2} \mathrm{O}_{3}$ composites are prepared by solvent evaporation casting. Scanning Electron Microscopy (SEM) images indicate that the embedded nanoparticles are well dispersed in the polymer matrix and X-Ray Diffraction (XRD) verifies the crystallinity of these Metal Oxides (MOs). Thermal stability analysis of PLA and PLA/MO composites is performed using a Thermogravimetric Analyzer (TGA) and Differential Scanning Calorimeter (DSC). The overall heat of combustion is measured by Microscale Combustion Calorimetry (MCC) and is found to be insensitive to the presence of nanoparticles.

The overall catalytic effects of the three metal oxides trends as: $\mathrm{Bi}_{2} \mathrm{O}_{3}>\mathrm{Fe}_{2} \mathrm{O}_{3}>\mathrm{CuO} \approx$ inert material. $\mathrm{PLA} / \mathrm{Bi}_{2} \mathrm{O}_{3}$ decomposition onset temperature $\left(\mathrm{T}_{5} \%\right)$ and maximum mass loss 
21 decomposition temperature $\left(\mathrm{T}_{\max }\right)$ are lowered by approximately $75 \mathrm{~K}$ and $100 \mathrm{~K}$ respectively

22 compared to the neat PLA. The as-synthesized $\mathrm{Bi}_{2} \mathrm{O}_{3}$ is identified as the most effective additive

23 among those proposed in the literature to catalyze the PLA thermal decomposition process. A

24 numerical pyrolysis modeling tool, ThermaKin, is utilized to analyze thermogravimetric data of

25 all the PLA/MOs and to produce a description of the decomposition kinetics, which can be utilized

26 for modeling of thermal vaporization of these sacrificial materials. 


\section{Introduction}

Poly Lactic Acid (PLA) is an environmentally friendly polymer produced from plants

30 (mainly from starch and sugar) including corn, potatoes and sugar-beets, and has attracted attention

31 for its biocompatibility, biodegradability, and thermoplastic processability. ${ }^{1}$ It has been reported

32 that the greenhouse gas emission rate of PLA is approximately $1600 \mathrm{~kg} \mathrm{CO}_{2} /$ metric ton, while that

33 of polypropylene (PE), polystyrene (PS), polyethylene terephthalate (PET), and nylon are 1850,

342740,4140 , and $7150 \mathrm{~kg} \mathrm{CO}_{2} /$ metric ton, respectively. ${ }^{2}$ Further, PLA's low temperature of thermal

35 degradation with minimal solid residue (gasified lactide) has made it an attractive candidate as a

36 sacrificial component in polymer fabrication. ${ }^{2-4}$

PLA is also one of the two major plastics explored as 3D printing inks (the other being

Acrylonitrile Butadiene Styrene (ABS)) because of its thermoplastic properties. ${ }^{5}$ Although ABS is

39 currently the dominant 3D printing polymer, PLA offers the advantage of bio-compatibility. As a

40 sacrificial component, PLA can be $3 \mathrm{D}$ printed to create complex-shaped molds ${ }^{6-8}$. For example,

41 White et al. ${ }^{7}$ have fabricated PLA as spheres (0D), fibers (1D), sheets (2D), and 3D printed

42 sacrificial materials, leaving behind the reverse replica. Pitet et al. ${ }^{9}$ have explored PLA as a

43 sacrificial component in copolymers to create porous membranes for battery separators utilizing the

44 fact that its decomposition temperature is about $200^{\circ} \mathrm{C}$ lower than thermally stable polymers such

45 as polyimide (PI), epoxies, Poly(vinylidene fluoride-hexafluoropropylene) (PVDF-HFP), etc. The

46 decomposition of neat PLA occurs above $\sim 550 \mathrm{~K}$, which can lead to the thermal instability of other

47 polymer blends in practical applications during prolonged heat treatment ${ }^{7}$. Therefore, alkali earth

48 metal oxides ${ }^{3}$, rare metal (scandium (III) triflates $\left.\left(\mathrm{CF}_{3} \mathrm{SO}_{3}-\right)\right)^{10}$, and tin-containing compounds ${ }^{7,8,11}$

49 were studied as catalysts for PLA thermal decomposition. Moore et al. ${ }^{6,7}$ added Sn-based reactants

50 to lower the decomposition temperature by $90 \mathrm{~K}$ to effectively remove sacrificial PLA at a lower 
51 temperature while avoiding thermal damage to the epoxy mold. It was found that the same amount

52 of $\mathrm{SnO}_{\mathrm{x}}$ additive works even better than tin (II) octoate to further reduce the total decomposition

53 time at the same temperature. ${ }^{7}$ Mori et al. reported similar results using Sn-based compounds and

54 recognized that these catalysts could enhance the breakage of ester bonds in the polymer backbone,

55 thus promoting the fragmented polymer ends to experience chain backbiting and transesterification

56 reactions before further depolymerization. ${ }^{11}$ Almost all of the previous studies used a high loading

57 of more than $5 \mathrm{wt} \%$ catalyst. $^{3,6-11}$

58 Addition of catalysts into PLA is usually achieved by surface treatment (including

59 impregnation or solvent swelling) ${ }^{6}$, solvent evaporation casting ${ }^{7}$, or vane extruding. ${ }^{12}$ Dong et al. ${ }^{6}$

60 utilized solvent swelling to immobilize metal ions (tin (II) octoate solution) into PLA fibers. Later,

61 Moore et al. used solvent evaporation to imbed $\mathrm{SnO}_{\mathrm{x}}$ into PLA, further decreasing the

62 decomposition temperature. ${ }^{7}$ Solvent evaporation casting of PLA with specific viscosity was

63 utilized by Guo et al. in a proposed 3D printing ink drying technique. ${ }^{13,14}$ Zhang et al. utilized

64 melt blending with a vane extruder with heating to get mono-dispersed $\mathrm{PLA} / \mathrm{TiO}_{2}$

65 nanocomposites. ${ }^{12}$

66 It is widely known that controlling the removal process of the sacrificial materials is extremely

67 difficult, requiring carefully designed thermal conditions and perfect timing to fully eliminate the

68 sacrificial material at minimal cost, while also keeping the host material undamaged. ${ }^{15}, 16$

69 Therefore, catalysts are added to increase the decomposition temperature difference between the

70 sacrificial materials and host materials to maintain the integrity of the host polymer. ${ }^{3,6-11}$ Usually

71 the removal time for even nano-scale channels are hours to days and are highly non-linear relative

72 to different heating conditions, which makes the control process hard to predict. ${ }^{6,7,15}$ The severity

73 of this problem increases as larger and more complex geometries are required with the rapid 
74 development of 3D printing using such sacrificial materials. ${ }^{13,14}$ MOs have not been studied

75 extensively as catalysts for PLA, especially at small loadings $(<5 \%)^{3,6,11}$.

76 In this work, we employed $1 \mathrm{wt} \%$ MOs loading to study the catalytic effects of $\mathrm{MOs} . \mathrm{Bi}_{2} \mathrm{O}_{3}$,

$77 \mathrm{CuO}$ and $\mathrm{Fe}_{2} \mathrm{O}_{3}$ are synthesized by spray pyrolysis ${ }^{17-19}$ and then uniformly embedded into PLA

78 matrix using solvent evaporation casting. XRD and SEM are performed to verify the additives'

79 crystallinity and homogenous dispersion in the PLA matrix. The thermal properties of PLA/MOs

80 composites relative to neat PLA are measured by TGA (Thermogravimetric Analyzer), DSC

81 (Differential Scanning Calorimeter), and MCC (Microscale Combustion Calorimeter) to examine

82 the MOs catalytic effect on the PLA's thermal degradation process and overall combustion heat.

83 Thermal degradation simulations are performed to fit the experimental TGA curve with a number

84 of first order chemical pyrolysis reaction models using a one dimensional pyrolysis model (-

85 ThermaKin ${ }^{20}$ running under thermally thin mode). This kinetic fitting work is preformed to

86 reproduce the TGA data, which provides kinetic fundamentals to potentially further predict and

87 control the removing process time and temperatures of PLA/MOs for different geometries or

88 length scales in various heating environments in the future.

\section{$\underline{\text { 2. Experimental }}$}

90 All metal oxide additives are in-house synthesized by aerosol spray pyrolysis. ${ }^{17-19}$ The spray

91 pyrolysis system (pictured in Figure 1) consists of an atomizer (to produce aerosol droplets), a

92 silica-gel diffusion drier (to remove solvent), an isothermal furnace (to decompose precursor

93 droplets), and a stainless steel sample collector with $0.4 \mu \mathrm{m}$ DTTP Millipore filter (to collect

94 nanoparticles). The aerosol droplets of precursor solution are generated using a collision-type

95 nebulizer with an initial droplet diameter of approximately $1 \mu \mathrm{m}$, which is then desiccated by

96 passing through the silica-gel diffusion dryer. The dehydrated aerosol precursors then decompose 
97 into the solid metal oxide particles in the tube furnace set at $600{ }^{\circ} \mathrm{C}$ for $\mathrm{Fe}_{2} \mathrm{O}_{3}$ and $\mathrm{CuO}$, or $1050^{\circ} \mathrm{C}$

98 for $\mathrm{Bi}_{2} \mathrm{O}_{3}$, with a residence time of about 1s. Particles exiting the aerosol reactor are then collected

99 on a $0.4 \mu \mathrm{m}$ pore size DTTP Millipore filter with $10 \%-20 \%$ porosity (EMD Millipore). The

100 precursors used for the $\mathrm{Bi}_{2} \mathrm{O}_{3}, \mathrm{Fe}_{2} \mathrm{O}_{3}$, and $\mathrm{CuO}$ are $\mathrm{Bi}\left(\mathrm{NO}_{3}\right)_{3} \cdot 5 \mathrm{H}_{2} \mathrm{O}, \mathrm{Fe}\left(\mathrm{NO}_{3}\right)_{3} \cdot 9 \mathrm{H}_{2} \mathrm{O}$ and

$101 \mathrm{Cu}\left(\mathrm{NO}_{3}\right)_{2} \cdot 3 \mathrm{H}_{2} \mathrm{O}$ respectively, all from Sigma-Aldrich. A total precursor concentration of $0.200 \mathrm{M}$

102 aqueous solution is used for MOs, and to dissolve $\mathrm{Bi}\left(\mathrm{NO}_{3}\right)_{3} \cdot 5 \mathrm{H}_{2} \mathrm{O}, 1: 5$ concentrated nitric acid 103 and water mixture is used as the solvent. The aerosol spray pyrolysis is a droplet to droplet method,

104 and the formation mechanism of MOs is described in Figure 1 below. Lognormal poly-dispersed

105 spherical solid particles are generated e.g. the $\mathrm{Fe}_{2} \mathrm{O}_{3}$ particles are spherical particles with a 106 lognormal distribution peak at $84 \mathrm{~nm} .{ }^{19}$

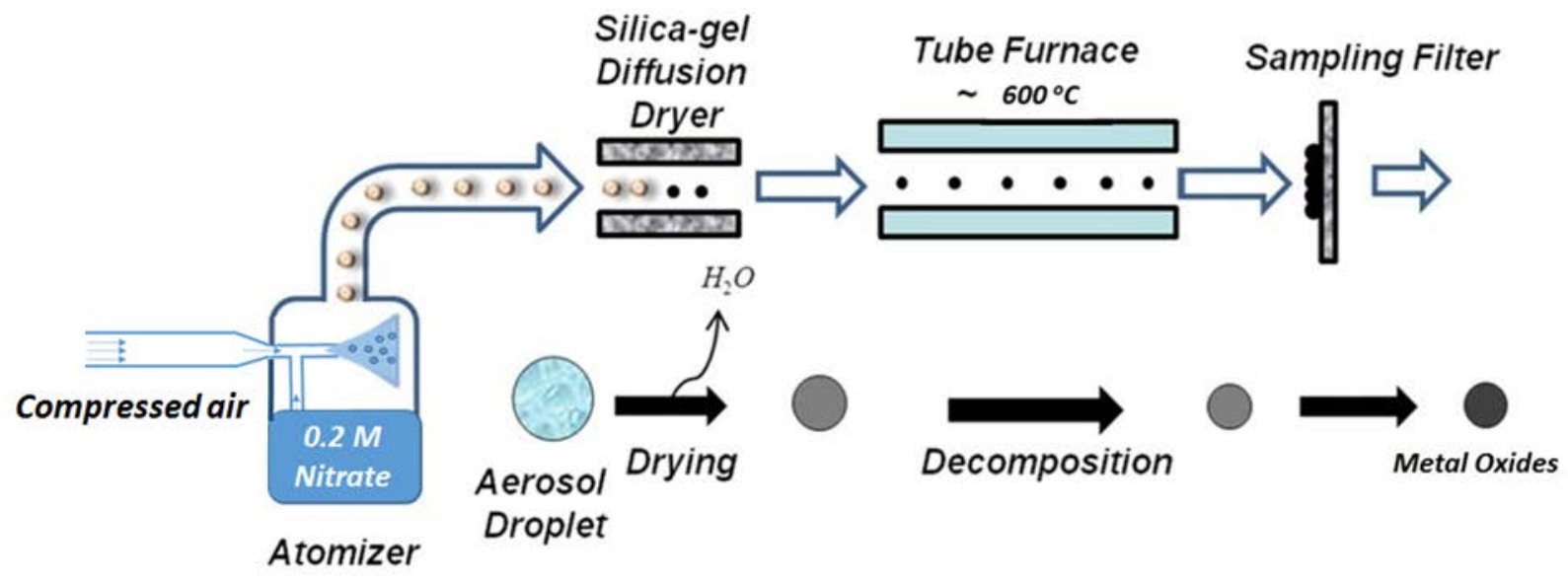

Figure 1. Aerosol spray pyrolysis synthesis system for metal oxides.

PLA (Rejuven8 Plus Spartech) is obtained from Nature Works and used as received. The

110 PLA sheets are $0.7 \mathrm{~mm}$ thick and cut into small pieces for solvent evaporation casting. $1.000 \mathrm{~g}$

111 PLA is first dissolved in $100.0 \mathrm{~mL} \mathrm{CH}_{2} \mathrm{Cl}_{2}$ with magnetic stirring for 30 mins. Then $10.0 \mathrm{mg}(1 \mathrm{wt} \%)$

$112 \mathrm{MO}$ is added to the solution and ultra-sonicated for $1 \mathrm{~h}$. The solutions are then poured onto a watch 113 glass and dried in a $50{ }^{\circ} \mathrm{C}$ convection oven to for $12 \mathrm{~h}$. Thin films of neat PLA (baseline reference) 
114 and PLA/MO composites are obtained after solvent evaporation. Small pieces of the as prepared

115 thin films were then used for the thermal tests. Crystal structures of metal oxides are characterized

116 by XRD with a Bruker Smart1000 using $\mathrm{Cu}$ Ka radiation. SEM results were obtained by Hitachi

117 SU-70 SEM. For cross-sectional SEM images, samples are first fractured in liquid nitrogen and

118 then sputter-coated with carbon. Nitrogen $\left(\mathrm{N}_{2}\right)$ adsorption-desorption isotherms and Brunauer-

119 Emmett-Teller (BET) surface were measured at $77 \mathrm{~K}$ with an Micromeritics ASAP 2020

120 Porosimeter.

121 A Netzsch F3 Jupiter Simultaneous Thermal Analyzer (STA), employed in the thermal stability 122 study, combines a TGA equipped with a $1 \mu \mathrm{g}$-resolution microbalance and DSC heat flow 123 measurement with a steel furnace. Thus the STA can measure the TGA and DSC signals 124 simultaneously during a single experiment. The PLA/MOs films were stored in a desiccator for 48 125 hours prior to testing, and then cut and pressed into Platinum-Rhodium crucibles with ventilation 126 lids with a sample mass of 6-7 $\mathrm{mg}$. The thermal decomposition experiments were performed at a 127 heating rate of $10 \mathrm{~K} \mathrm{~min}^{-1}$ from $40{ }^{\circ} \mathrm{C}$ to $600{ }^{\circ} \mathrm{C}$ under $99.999 \%$ (UHP) $\mathrm{N}_{2}$ at a flow rate of 50 $128 \mathrm{~cm}^{3} \cdot \mathrm{min}^{-1}$. A microscale combustion calorimeter (MCC) with $3 \mathrm{mg}$ samples was used to measure 129 the heat release rate and total heat of combustion. ${ }^{1}$ The MCC combines a condensed phase 130 pyrolyzer and gas phase combustor. The samples are first decomposed in $80 \mathrm{~cm}^{3} \mathrm{~min}^{-1}$ UHP $\mathrm{N}_{2}$ 131 flow, $60 \mathrm{~K} \mathrm{~min}^{-1}$ heating rate from 75 to $600{ }^{\circ} \mathrm{C}$ inside the pyrolyzer, which is similar to the STA 132 furnace, and then transferred to the combustor where the gaseous fuel (decomposition products) 133 was burned at $950{ }^{\circ} \mathrm{C}$ to ensure complete combustion mixing with additional $20 \mathrm{~cm}^{3} \cdot \mathrm{min}^{-1} \mathrm{O}_{2}$. The 134 entire experimental measurement of HRR (Heat Release Rate) followed ASTM standard ASTM 135 D 7309-13. ${ }^{21}$ The heat release rate was measured based on Thornton's rule by measuring the $\mathrm{O}_{2}$ 136 consumption rate of combustion. ${ }^{22}$ 
138 Figure 2 shows the SEM micrographs of spray pyrolysis synthesized $\mathrm{Bi}_{2} \mathrm{O}_{3}, \mathrm{Fe}_{2} \mathrm{O}_{3}$ and $\mathrm{CuO}$ 139 nanoparticles, which are solid spherical particles with diameters from $50 \mathrm{~nm}$ to $1 \mu \mathrm{m}$ following a $140 \log$ normal distribution with a peak $\left(\mathrm{Fe}_{2} \mathrm{O}_{3}\right.$ at $84 \mathrm{~nm}^{19}, \mathrm{CuO}$ at $86 \mathrm{~nm}$ and $\mathrm{Bi}_{2} \mathrm{O}_{3}$ at $87 \mathrm{~nm}$, shown 141 in Figure S1). Figure S2 shows BET surface area results: $\mathrm{Fe}_{2} \mathrm{O}_{3}-13 \mathrm{~m}^{2} / \mathrm{g}, \mathrm{CuO}-23 \mathrm{~m}^{2} / \mathrm{g}, \mathrm{Bi}_{2} \mathrm{O}_{3}-4$ $142 \mathrm{~m}^{2} / \mathrm{g}$, with $\mathrm{Bi}_{2} \mathrm{O}_{3}$ surface area being the lowest, indicating that surface area does not explain the 143 superior catalytic activity of $\mathrm{Bi}_{2} \mathrm{O}_{3}$. The crystal structure of oxides are investigated from XRD 144 shown in Figure S3. All peaks in $\mathrm{Fe}_{2} \mathrm{O}_{3}$ can be indexed to $\gamma-\mathrm{Fe}_{2} \mathrm{O}_{3}$ phase (JCPDS card No.: 39145 1346); $\mathrm{Bi}_{2} \mathrm{O}_{3}$ with JCPDS card No.: 27-0050, while $\mathrm{CuO}$ peaks corresponds to tenorite with 146 JCPDS card No.: 48-1548.

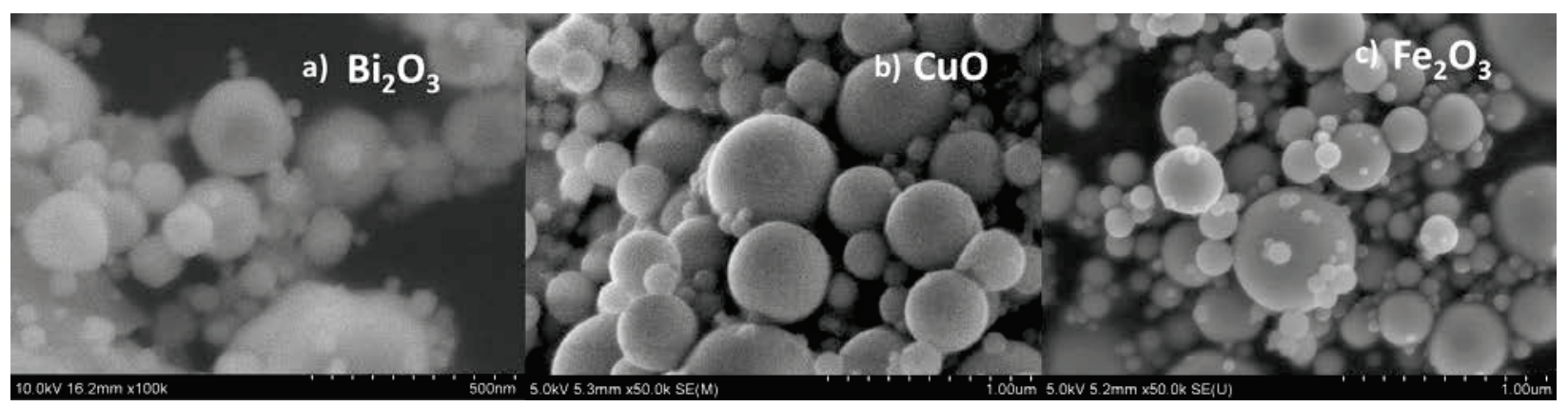

Figure 2. SEM of nanoparticles a) $\mathrm{Bi}_{2} \mathrm{O}_{3}$, b) $\mathrm{CuO}$, c) $\mathrm{Fe}_{2} \mathrm{O}_{3}$, prepared from spray pyrolysis. It is widely known that the dispersion of nanoparticles in polymer will greatly influence

150 the both chemical and physical properties of the PLA/MO composites. Homogeneous dispersion 151 of MO nanoparticles will affect the thermal and mechanical behaviors of PLA, such as wettability, 152 UV transmittance, strength and ductility, elasticity, viscosity, antibacterial property. ${ }^{12}$ Cross-sectional SEM images are taken to check the dispersion of MOs in the composites.

154 PLA/MOs are first fractured in liquid nitrogen and then broken off for cross-sectional images. 
155 Figure 3a) and 3b) show neat PLA cross-sectional image without particles, and Figure 3c) and 3d) 156 are $\mathrm{PLA} / \mathrm{Fe}_{2} \mathrm{O}_{3}, \mathrm{PLA} / \mathrm{CuO}$ films images, respectively. It is clear from these images that all 157 nanoparticles are well dispersed in the PLA films. Figure 4 shows the cross-sectional PLA/ $/ \mathrm{Bi}_{2} \mathrm{O}_{3}$ 158 structure, and it is clear that spherical $\mathrm{Bi}_{2} \mathrm{O}_{3}$ are uniformly dispersed in PLA and un-aggregated. 159 The film is about $50 \mu \mathrm{m}$ thick, indicated by low magnification image of Figure 4a) and Figure $4 \mathrm{~b}$ ). 160 Moreover, Figure 4c) and 4d) give a closer view of the cross-sections, all showing that particles 161 are coated and/or connected by PLA while separated from other nanoparticles. 


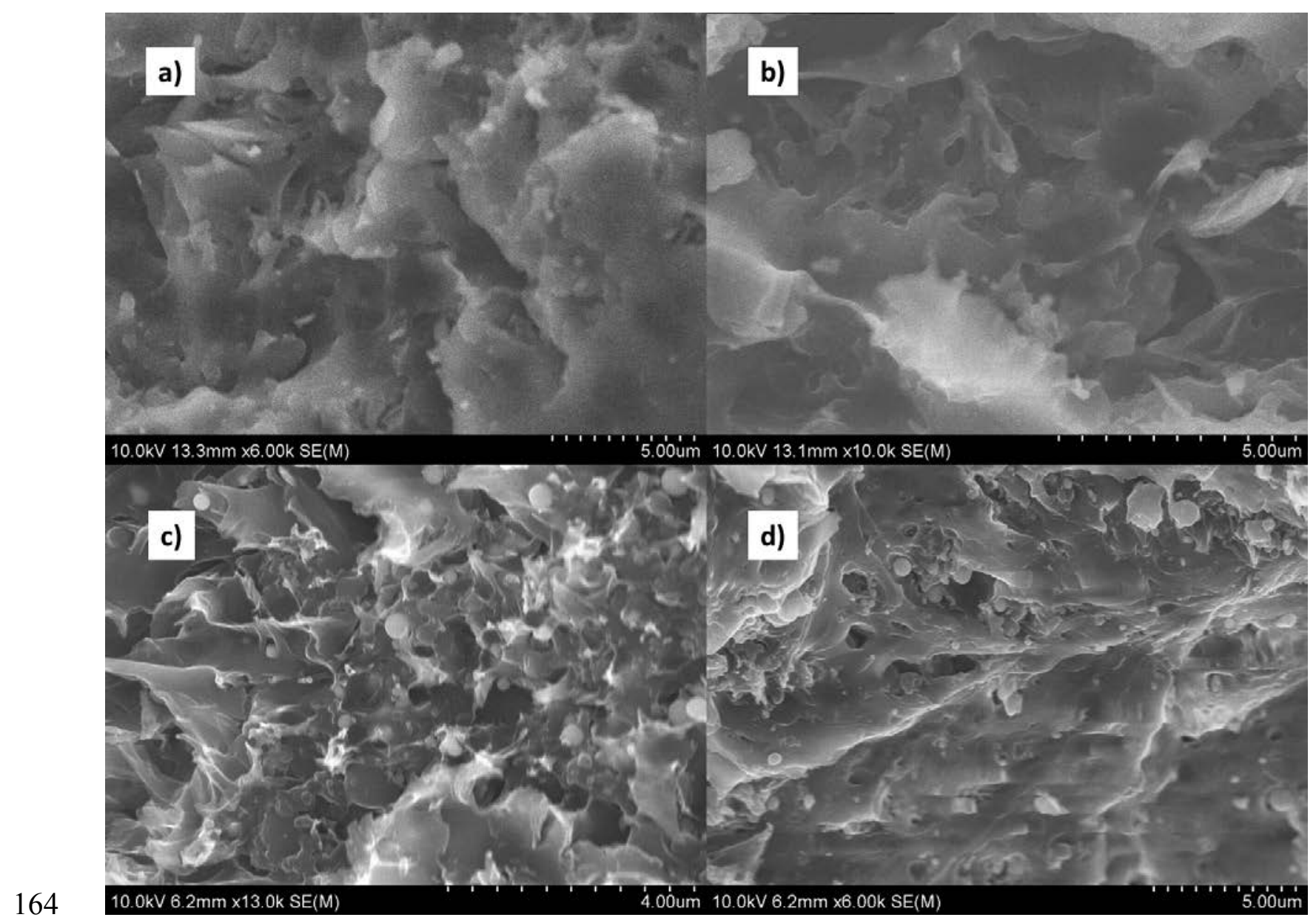

165 Figure 3. SEM of cross-sectioned a) and b) PLA, c) PLA/ $\mathrm{Fe}_{2} \mathrm{O}_{3}$, d) PLA/CuO films. 


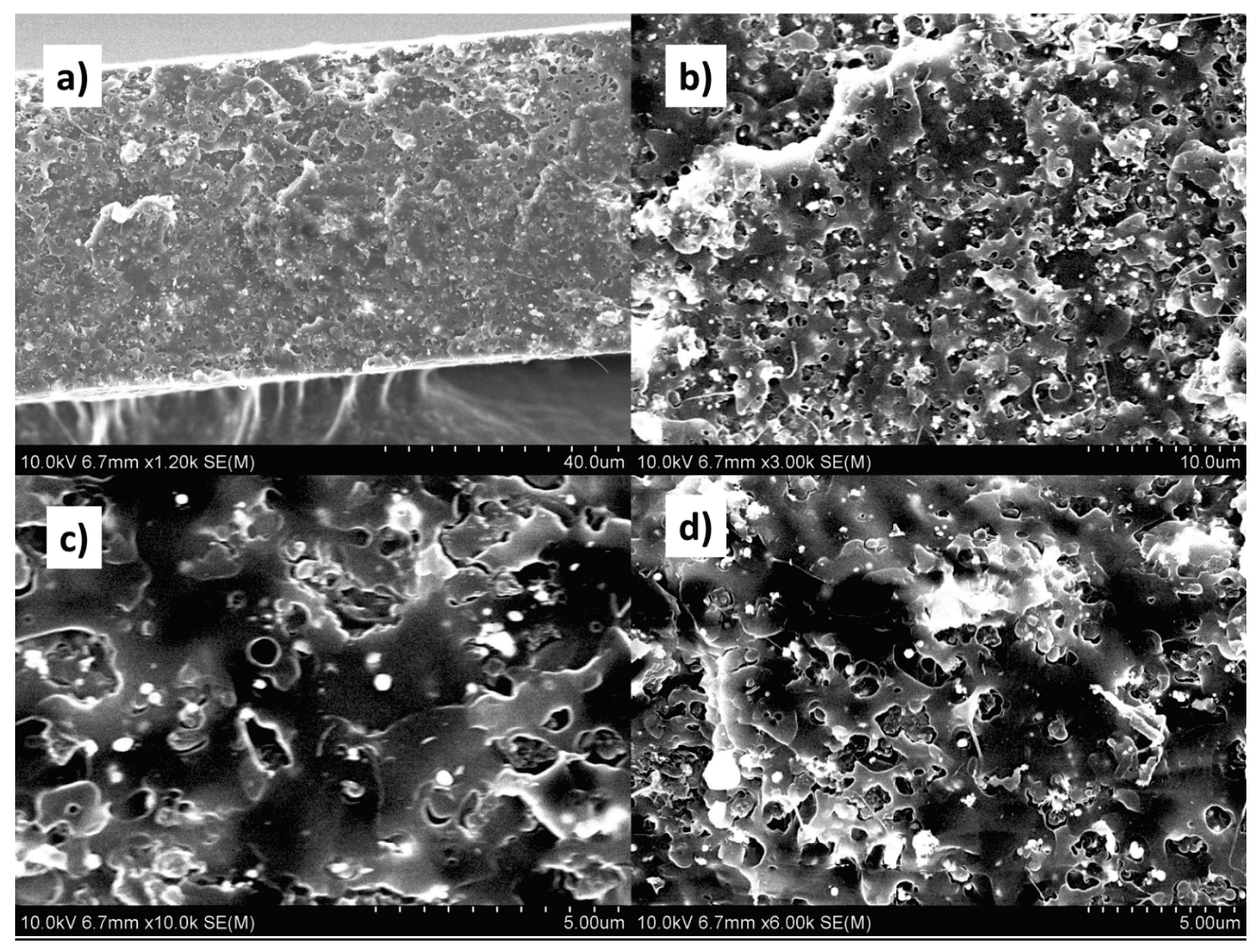

Figure 4. SEM of cross-sectioned $\mathrm{PLA} / \mathrm{Bi}_{2} \mathrm{O}_{3}$ film.

Figure 5 shows the TGA data of thermal decomposition mass loss under $\mathrm{N}_{2}$ inert

169 atmosphere. It is clear that the various types of MO additives affect the thermal stabilities of

170 PLA/MOs differently, which can also be clearly seen in Figure 6 from Derivative

171 Thermogravimetry (DTG) experimental curves (dotted lines). Specifically, the onset thermal

172 degradation temperature for neat PLA as a reference is approximately $\mathrm{T}_{5 \%} \approx 580 \mathrm{~K}$. For

$173 \mathrm{PLA} / \mathrm{Bi}_{2} \mathrm{O}_{3}$, this temperature is $75 \mathrm{~K}$ lower $\left(\mathrm{T}_{5} \% \approx 505 \mathrm{~K}\right)$, while the effect of $\mathrm{Fe}_{2} \mathrm{O}_{3}$ is about $30 \mathrm{~K}$

174 decrease $\left(\mathrm{T}_{5 \%} \approx 550 \mathrm{~K}\right)$ compared to neat PLA; CuO shows no noticeable effect. The thermal

175 degradation temperatures at maximum weight loss $\left(\mathrm{T}_{\max }\right)$, are $536 \mathrm{~K}(614 \mathrm{~K}$ for the second peak), 
$176573 \mathrm{~K}, 634 \mathrm{~K}$ and $635 \mathrm{~K}$ for PLA/ $\mathrm{Bi}_{2} \mathrm{O}_{3}, \mathrm{PLA} / \mathrm{Fe}_{2} \mathrm{O}_{3}, \mathrm{PLA} / \mathrm{CuO}$ and neat PLA respectively. These

177 results show that the catalytic properties trend as: $\mathrm{Bi}_{2} \mathrm{O}_{3}>\mathrm{Fe}_{2} \mathrm{O}_{3}>\mathrm{CuO}$. While the DSC signals

178 reveal notable differences at the stage of decomposition, the addition of MOs does not significantly

179 affect the melting point $\sim 425 \mathrm{~K}$ or the heat of melting (as seen in DSC Figure 7). The heats of 180 melting (the first peak integrals) are within $4 \%$ difference of their mean.

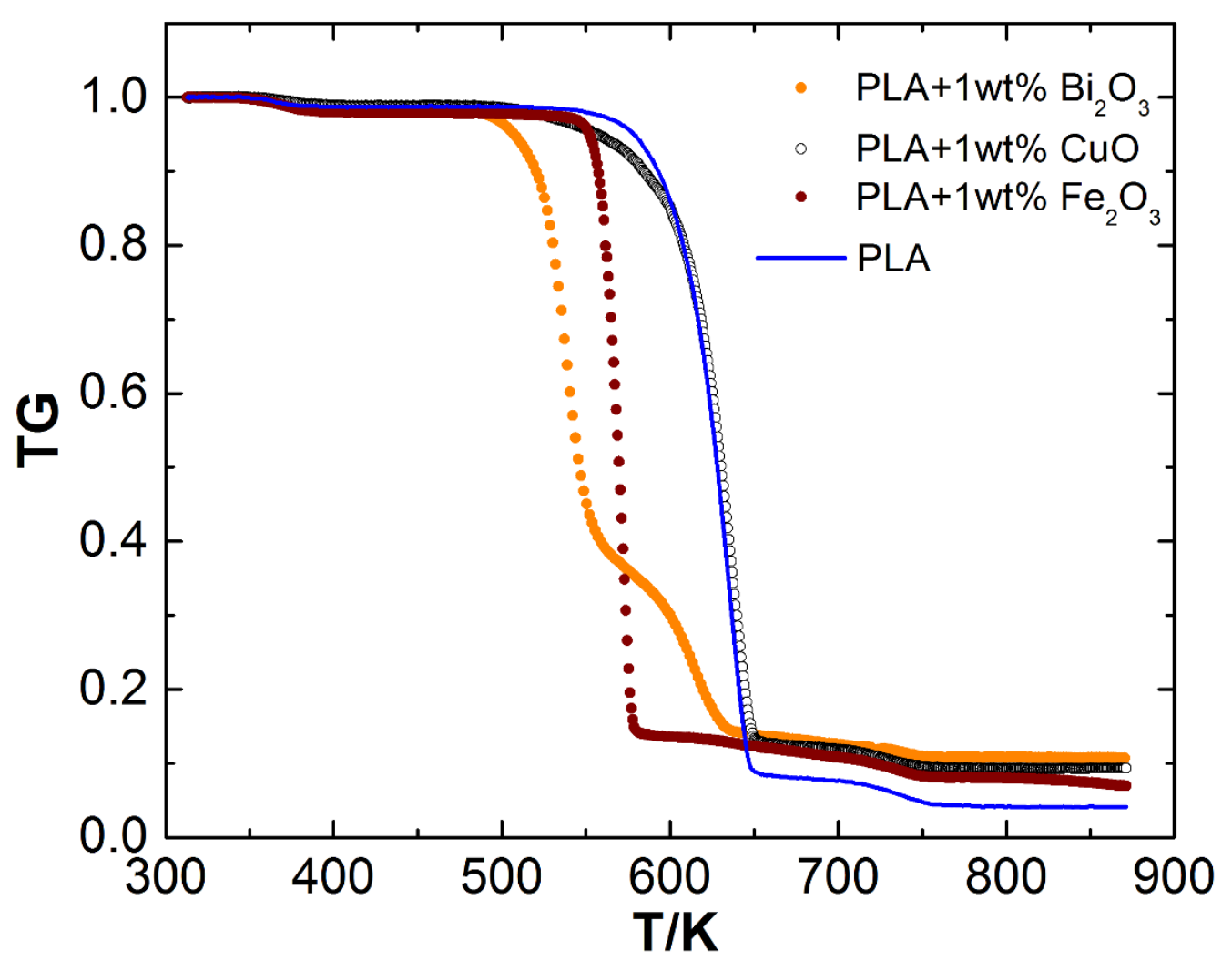

181 


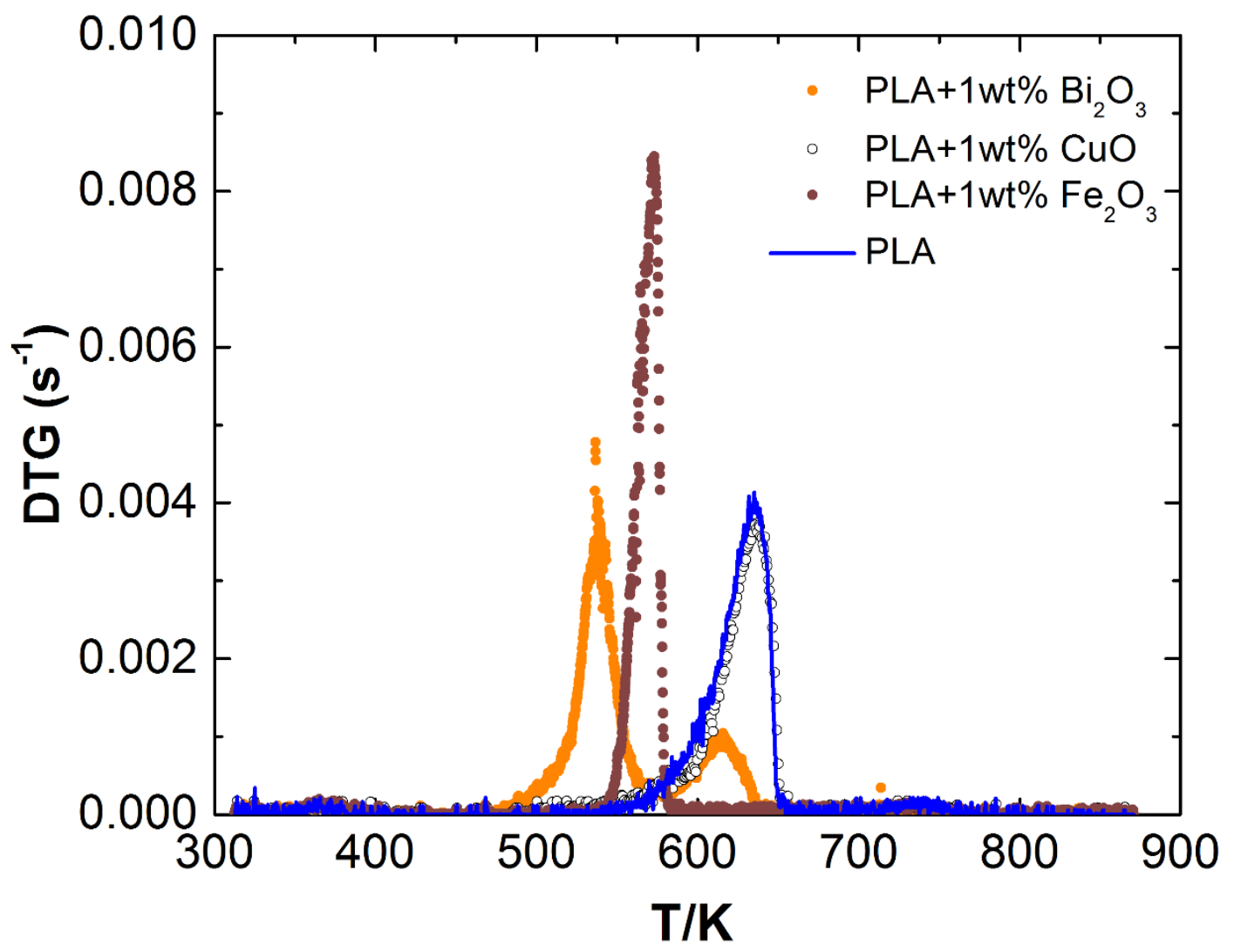

183

Figure 6. DTG plots of PLA and PLA/MOs.

To better evaluate the decomposition kinetics at various heating conditions and scales,

186 which are necessary as fundamentals to predict the catalytic effects of the MOs on the PLA

187 decomposition, we have extracted phenomenological rate parameters using a numerical pyrolysis

188 software - ThermaKin. ${ }^{20}$ ThermaKin solves the mass and energy conservation equations

189 numerically for one or two dimensional objects exposed to external (convective and/or radiative)

190 heat. In this study, we use the thermally thin mode to simulate the thermal degradation processes

191 inside the STA furnace. The material of the object (sample) is described by multiple components,

192 which may interact chemically and physically. The neat PLA and PLA/MOs kinetics were 
193 characterized using the methodology reported in our recent publications. ${ }^{23}$ This methodology has

194 been successfully applied to reproduce TGA and DSC signals of 15 non-charring and charring 195 polymers. ${ }^{23,24}$ The resulting kinetic parameters were also shown to predict gasification or burning 196 rates of these polymers at a wide range of thermal conditions. ${ }^{23-26}$ was modeled using two consecutive first order reactions. ${ }^{23}$ One more reaction was employed to 199 describe melting $\left(T_{\text {melt }}=425 \mathrm{~K}\right)$. This was done to use a minimum number of parameters to 200 describe the entire time-resolved TGA and DSC curves. The kinetics of those reactions are 201 parameterized with Arrhenius parameters $\left(A_{\mathrm{x}}, E_{\mathrm{x}}\right.$ represent decomposition reaction x; while $A_{\mathrm{m}}$, $202 E_{\mathrm{m}}$ represent the melting) listed in Table 1 . The value of the $\theta_{x}$ is calculated by the instantaneous 203 mass (at the end stage of the reaction $\mathrm{x}$ ) over its initial mass. Note that the $\theta_{\mathrm{x}}$, obtained directly 204 from the TGA experiments, corresponds to the remaining condensed phase residue yielded in the 205 reaction $\mathrm{x}$. Those parameters are initially estimated using simple analytical expressions ${ }^{27}$ and then 206 changed in small increments following the rules summarized in the previous studies until 207 agreements with the experiment is reached (based on preset coefficient of determination and visual 208 comparison). Each model reaction corresponds to tens or, perhaps, hundreds of elementary 209 chemical processes operating within the same range of temperatures.

210 The MOs do not affect the phase transition as evident from DSC curves in Figure 7 (enlarged 211 temperature range in the left corner). The kinetic parameters describing the melting were reported 212 previously $^{23}$. For all the PLA composites, MOs are found to affect the thermal degradation process 213 significantly, which is apparent in both the TGA and DSC measurements. The impact of MOs on 214 the kinetics of decomposition is quantified through changes in the parameters of the first (major) 215 reaction. The kinetic parameters are summarized in Table 1. With the exception of PLA/ $\mathrm{Bi}_{2} \mathrm{O}_{3}$, 
216 the decomposition of all composites can be described by two consecutive reactions. The kinetics

217 of the second reaction remain unaffected by the addition of MOs. In the case of PLA/ $/ \mathrm{Bi}_{2} \mathrm{O}_{3}$, the

218 thermal decomposition process consists of three consecutive reactions reflecting a more complex

219 DTG signal. It has been widely concluded that the thermal decomposition of pure PLA is a one-

220 stage reaction that involves the loss of ester groups in pure nitrogen ${ }^{28}$ and air $^{29,30}$, consistent with

221 our observations for neat PLA and PLA/CuO in this study. Other researchers have also observed

222 multiple reaction steps with the addition of other catalysts ${ }^{6}$, although little information on

223 mechanism is available. Our speculation for the existing second peak is that part of the PLA

224 remains unaffected by the catalytic $\mathrm{Bi}_{2} \mathrm{O}_{3}$ during the first decomposition step, and it decomposes

225 as neat PLA at a higher temperature to form the second peak. Further investigation is required to 226 validate this hypothesis.

227 For all the materials, the solid lines in Figure 8 represent the numerical simulation results

228 from the ThermaKin. All the simulation results fit the experimental data well and the calculated

229 coefficients of determination of the experimental data and the fitted curves are all above 0.9. 


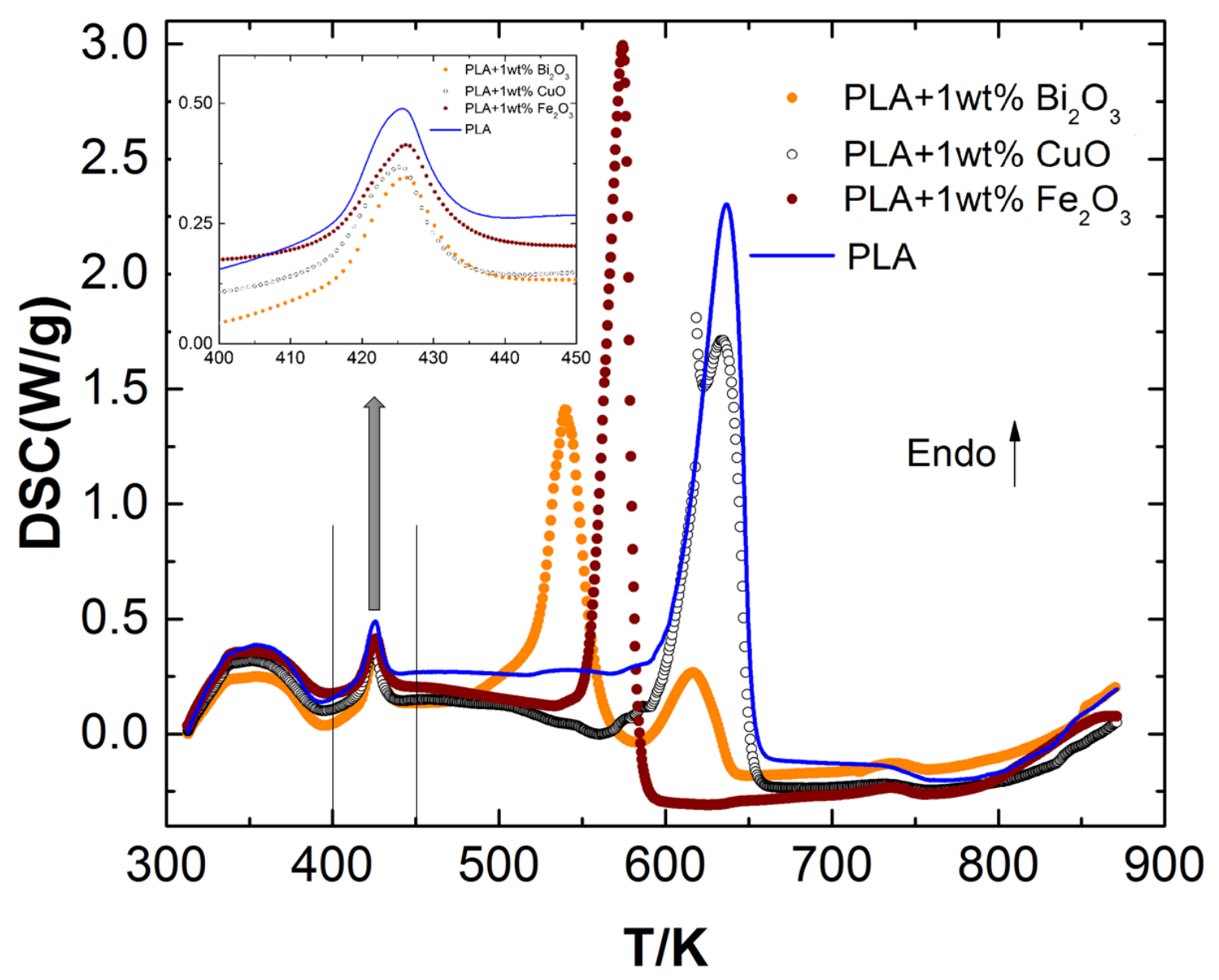

Figure 7. DSC test of PLA and PLA/MOs. 


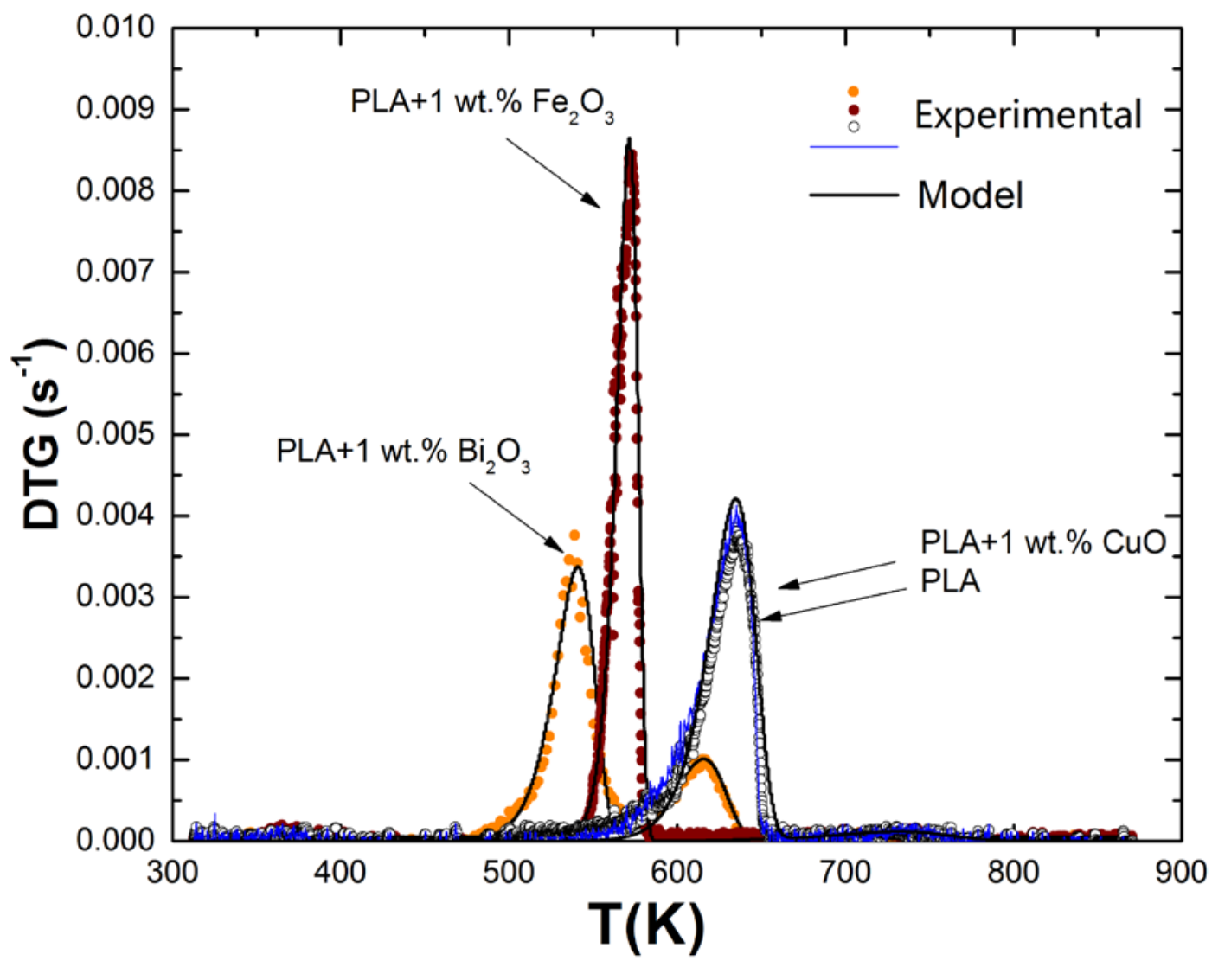

233 Figure 8. Experimental and simulated DTG of PLA \& PLA/MO composites at $10 \mathrm{~K} \mathrm{~min}^{-1}$.

234

\begin{tabular}{|c|c|c|c|c|c|c|c|c|c|c|c|}
\hline Polymer & $\begin{array}{c}A_{1} \\
\left(\mathrm{~s}^{-1}\right)\end{array}$ & $\begin{array}{c}E_{1} \\
\left(\mathrm{~kJ} \mathrm{~mol}^{-1}\right)\end{array}$ & $\theta_{1}$ & $\begin{array}{c}A_{2} \\
\left(\mathrm{~s}^{-1}\right)\end{array}$ & $\begin{array}{c}E_{2} \\
\left(\mathrm{~kJ} \mathrm{~mol}^{-1}\right)\end{array}$ & $\theta_{2}$ & $\begin{array}{c}A_{3} \\
\left(\mathrm{~s}^{-1}\right)\end{array}$ & $\begin{array}{c}E_{3} \\
\left(\mathrm{~kJ} \mathrm{~mol}^{-1}\right)\end{array}$ & $\theta_{3}$ & $\begin{array}{c}A_{m} \\
\left(\mathrm{~s}^{-1}\right)\end{array}$ & $\begin{array}{c}E_{\mathrm{m}} \\
\left(\mathrm{kJ} \mathrm{mol}^{-1}\right)\end{array}$ \\
\hline PLA & $1.68 \mathrm{E} 18$ & 245 & 0.1 & $4.58 \mathrm{E} 6$ & 126 & 0.4 & $\mathrm{~N} / \mathrm{A}$ & N/A & N/A & $6.0 \mathrm{E} 40$ & 355 \\
\hline $\mathrm{Fe}_{2} \mathrm{O}_{3}$ & $1.80 \mathrm{E} 38$ & 436 & 0.14 & $4.58 \mathrm{E} 6$ & 126 & 0.5 & N/A & N/A & N/A & $6.0 \mathrm{E} 40$ & 355 \\
\hline
\end{tabular}




\begin{tabular}{|c|c|c|c|c|c|c|c|c|c|c|c|}
\hline $\begin{array}{c}\text { PLA+ } \\
\mathrm{Bi}_{2} \mathrm{O}_{3}\end{array}$ & $1.34 \mathrm{E} 18$ & 207 & 0.38 & $2.85 \mathrm{E} 15$ & 205.5 & 0.37 & $4.58 \mathrm{E} 6$ & 126 & 0.72 & $6.0 \mathrm{E} 40$ & 355 \\
\hline $\mathrm{PLA}+$ & $1.68 \mathrm{E} 18$ & 245 & 0.1 & $4.58 \mathrm{E} 6$ & 126 & 0.4 & N/A & N/A & N/A & $6.0 \mathrm{E} 40$ & 355 \\
$\mathrm{CuO}$ & & & & & & & & & & \\
\hline
\end{tabular}

235 Table 1 Kinetic parameters for PLA, PLA/Fe $\mathrm{O}_{3}, \mathrm{PLA} / \mathrm{Bi}_{2} \mathrm{O}_{3}$ and PLA/CuO.

236 The Heat Release Rate(HRR) is measured by MCC, as shown in the Figure 9. The heat

237 release rate curves for all the PLA/MOs composites match the reaction peaks of TGA and DSC

238 qualitatively but not quantitatively with respect to their peak temperatures. The corresponding heat

239 release rate peaks in Figure 9 for all the samples shift to a higher temperature by approximately 27

$240 \sim 28 \mathrm{~K}$ compared to the DTG and DSC results in Figures $6 \& 7$. 


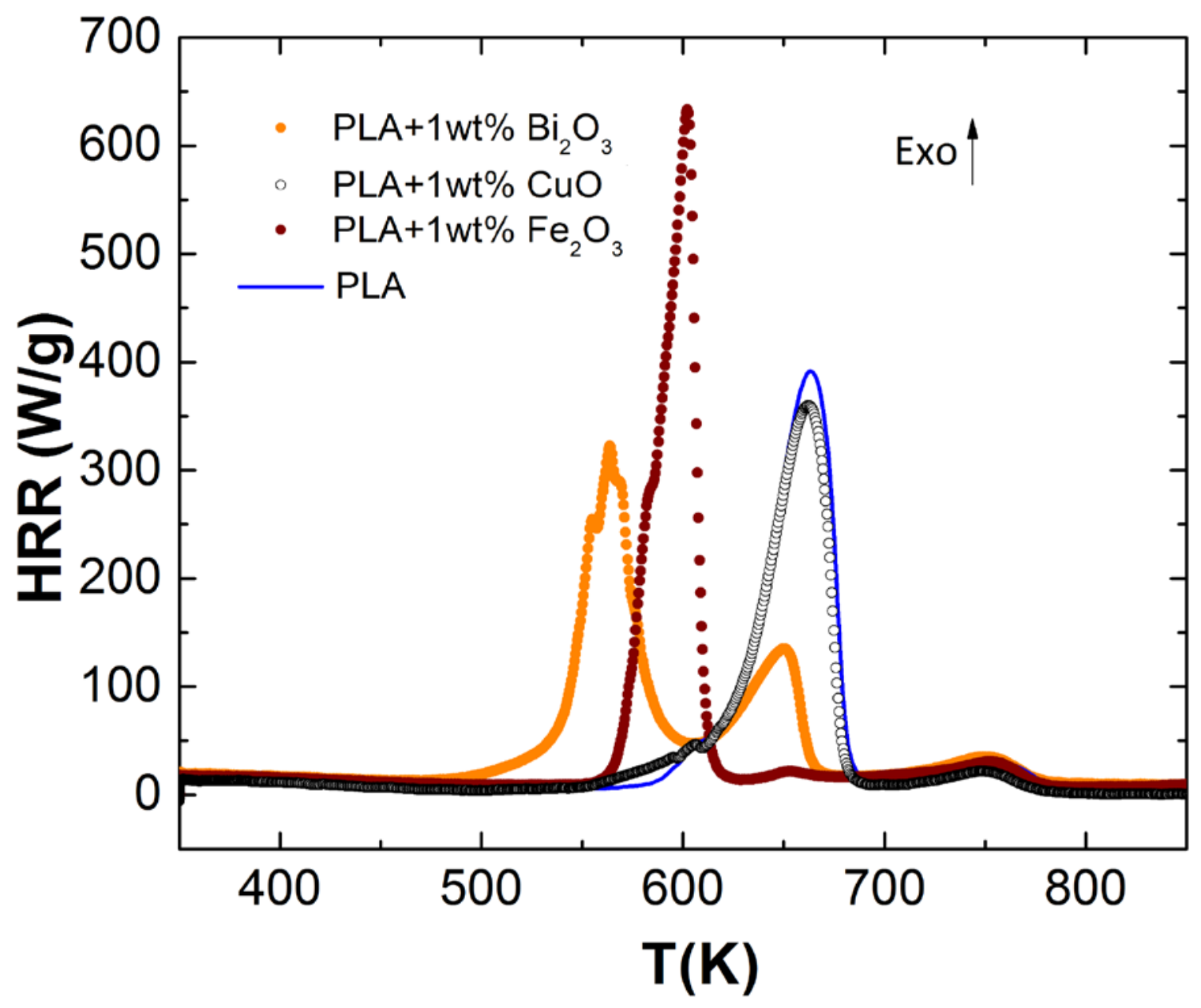

Figure $9 \mathrm{HRR}$ of PLA, PLA/ $\mathrm{Fe}_{2} \mathrm{O}_{3}, \mathrm{PLA} / \mathrm{Bi}_{2} \mathrm{O}_{3}$ and $\mathrm{PLA} / \mathrm{CuO}$.

This temperature difference is caused by the relatively higher heating rate $\left(60 \mathrm{~K} \mathrm{~min}^{-1}\right)$

244 utilized in the MCC compared to the heating rate $\left(10 \mathrm{~K} \mathrm{~min}^{-1}\right)$ in the STA test. The integral of the

245 heat release rate, which accounts for the heat of combustion of the gaseous decomposition products,

246 is approximately equal for all tested samples yielding $19.5 \pm 0.8 \mathrm{~kJ} / \mathrm{g}$. Therefore, all of the these

247 three types of $1 \mathrm{wt} \%$ PLA/MOs affect the thermal degradation processes only in the condensed 248 phase but have no effect on the heat of combustion. 


\section{Conclusion}

In this paper, we offer a facile method to incorporate metal oxide additives and evaluate

251 their catalytic effects on PLA thermal decomposition. More specifically, we have explored $\mathrm{Bi}_{2} \mathrm{O}_{3}$,

$252 \mathrm{CuO}$ and $\mathrm{Fe}_{2} \mathrm{O}_{3}$ nanoparticles as catalysts for PLA thermal decomposition. $\mathrm{Bi}_{2} \mathrm{O}_{3}$ is shown to be a

253 highly effective catalyst for PLA thermal decomposition. With only $1 \mathrm{wt} \%$ loading, it lowered the

254 onset decomposition temperature $\left(\mathrm{T}_{5 \%}\right)$ by $75 \mathrm{~K}$ and the decomposition temperature at the 255 maximum weight loss $\left(\mathrm{T}_{\max }\right)$ by approximate $100 \mathrm{~K}$, comparable to the most effective catalysts 256 studied so far. The same amount of $\mathrm{Fe}_{2} \mathrm{O}_{3}$ and $\mathrm{CuO}$ nanoparticles have moderate and negligible 257 effects on PLA thermal decomposition processes respectively. The overall catalytic effects of the 258 three metal oxides trend as: $\mathrm{Bi}_{2} \mathrm{O}_{3}>\mathrm{Fe}_{2} \mathrm{O}_{3}>\mathrm{CuO} \approx$ inert material.

$260 \mathrm{MCC}$, in which 1wt\% MO additive catalyzes the thermal degradation processes differently in the 261 condensed phase, and moreover, have negligible effect on the complete combustion heat in the

262 gas phase as expected. PLA/MOs decomposition was then quantatatively analysed to extract

263 Arrhenious parameters for the decomposition kinetics, which offers possible explanations and 264 predictions to evaluate thermal decompostion kinetics at other heating rate conditions.

\section{Acknowledgement}

266 This work was partially supported by faculty research fund from the University of New 267 Haven. The authors would like to thank Ms. Xi Ding for conducting the MCC tests.

\section{$\underline{\text { 6. Reference }}$}

269 1. R. E. Drumright, P. R. Gruber and D. E. Henton, Advanced Materials, 2000, 12, 1841$270 \quad 1846$.

271 2. Y. Fan, H. Nishida, Y. Shirai, Y. Tokiwa and T. Endo, Polymer Degradation and Stability, 272 2004, 86, 197-208. 
3. Y. Fan, H. Nishida, T. Mori, Y. Shirai and T. Endo, Polymer, 2004, 45, 1197-1205. C. Gottschalk and H. Frey, Macromolecules, 2006, 39, 1719-1723.

6. H. Dong, A. P. Esser-Kahn, P. R. Thakre, J. F. Patrick, N. R. Sottos, S. R. White and J. S. Moore, ACS Applied Materials \& Interfaces, 2012, 4, 503-509.

7. R. C. R. Gergely, S. J. Pety, B. P. Krull, J. F. Patrick, T. Q. Doan, A. M. Coppola, P. R. Thakre, N. R. Sottos, J. S. Moore and S. R. White, Advanced Functional Materials, 2015, 25, 1043-1052.

8. F. Carrasco, P. Pagès, J. Gámez-Pérez, O. O. Santana and M. L. Maspoch, Polymer Degradation and Stability, 2010, 95, 116-125.

9. L. M. Pitet, M. A. Amendt and M. A. Hillmyer, J Am Chem Soc, 2010, 132, 8230-8231.

10. T. S. Coope, U. F. J. Mayer, D. F. Wass, R. S. Trask and I. P. Bond, Advanced Functional Materials, 2011, 21, 4624-4631.

11. T. Mori, H. Nishida, Y. Shirai and T. Endo, Polymer Degradation and Stability, 2004, 84, 243-251.

12. H. Zhang, J. Huang, L. Yang, R. Chen, W. Zou, X. Lin and J. Qu, RSC Advances, 2015, 5, 4639-4647.

13. S.-Z. Guo, F. Gosselin, N. Guerin, A.-M. Lanouette, M.-C. Heuzey and D. Therriault, Small, 2013, 9, 4118-4122.

14. S.-z. Guo, X. Yang, M.-C. Heuzey and D. Therriault, Nanoscale, 2015, 7, 6451-6456.

15. H. A. Reed, C. E. White, V. Rao, S. Ann, B. Allen, C. L. Henderson and P. A. Kohl, J. Micromech. Microeng., 2001, 11, 733-737.

16. S. Metz, S. Jiguet, A. Bertsch and P. Renaud, Lab on a Chip, 2004, 4, 114-120.

17. C. Wu, K. Sullivan, S. Chowdhury, G. Jian, L. Zhou and M. R. Zachariah, Advanced Functional Materials, 2012, 22, 78-85.

18. G. Jian, L. Liu and M. R. Zachariah, Advanced Functional Materials, 2013, 23, 1341-1346.

19. L. Liu and M. R. Zachariah, Energy \& Fuels, 2013, 27, 4977-4983.

20. S. I. Stoliarov and R. E. Lyon, Thermo-Kinetic Model of Burning, Federal Aviation Administration Technical Note, 2008.

21. ASTM(D7309-13), Standard Test Method for Determining Flammability Characteristics of Plastics and Other Solid Materials Using Microscale Combustion Calorimetry 7309, 2013.

22. W. Thornton, Philosophical Magazine and J. of Science, 1917, 33, 196-203.

23. J. Li and S. I. Stoliarov, Combust Flame, 2013, 160, 1287-1297.

24. J. Li, J. Gong and S. I. Stoliarov, Int J Heat Mass Tran, 2014, 77, 738-744.

25. J. Li and S. I. Stoliarov, Polymer Degradation and Stability, 2014, 106, 2-15.

26. J. Li, J. Gong and S. I. Stoliarov, Polymer Degradation and Stability, 2015, 115, 138-152.

27. R. E. Lyon, R. N.Walters and S. I. Stoliarov, Journal of ASTM International, 2006, 3, 118.

28. M. A. G. Cristian-Andi Nicolae, Raluca Augusta Gabor, Engineering Letter, 2008, 16.p568

29. M. C. G. a. V. G. Deshmukh, Coll Polym. Sci.,, 1982, 260, 514-517.

30. M. C. G. a. V. G. Deshmukh, Coll. Polym. Sci, 1982, 260, 308-311. 
(n) 